\title{
Validation of HIV Risk Screening Tool To Identify Infected Adults And Adolescents >14 Years At Community Level
}

Kesetebirhan Delele Yirdaw ( $\sim$ kesetebirhan@gmail.com )

Integrated Services for Health and Development Organization

Justin Mandala

Family Health International

\section{Research Article}

Keywords: Adult HIV risk assessment tool, Undiagnosed HIV, Never tested for HIV, HIV testing yield

Posted Date: July 14th, 2021

DOI: https://doi.org/10.21203/rs.3.rs-668957/v1

License: (c) (i) This work is licensed under a Creative Commons Attribution 4.0 International License. Read Full License 


\section{Abstract}

\section{Background}

There are a number of risk factors being used to identify undiagnosed HIV infected adults. As the number of undiagnosed people gets lesser and lesser, it is important to know if existing risk factors and risk assessment tools are valid for use. In this study, we validate existing HIV risk assessment tools and see if they are worth using for HIV case finding among adults who remain undiagnosed.

\section{Methods}

The Tanzania and Zambia Population-Based HIV Impact Assessment (PHIA) household surveys were conducted during 2016. We used adult interview and HIV datasets to assess validity of different HIV risk assessment tools. We first included 12 risk factors (being divorced, separated or widowed (DSW); having an HIV+ spouse; having one of the following within 12 months of the survey: paid work, slept away from home for at least a month, had multiple sexual partners, paid for sex, had sexually transmitted infection (STI), being a tuberculosis (TB) suspect, being very sick for at least 3 months; had ever sold sex; diagnosed with cervical cancer; and had TB disease into a risk assessment tool and assessed its validity by comparing it against HIV test result. Sensitivity, specificity and predictive value of the tool were assessed against the HIV test result. A receiver operator characteristic ( $\mathrm{ROC}$ ) analysis was conducted to determine a suitable cut-off score in order to have a tool with better sensitivity, specificity, and PPV. ROC comparison statistics was used to statistically test equality between AUC (area under the curve) of the different scores. ROC comparison statistics was also used to determine which risk assessment tool was better compared to the tool that contained all risk factors.

\section{Results}

Of 14,820 study participants, $57.8 \%$ were men, and had a median age of 30 (IQR: 21-24). HIV prevalence was $2.3 \%$ (95\% confidence interval (CI): 2.0-2.6). For the tool containing all risk factors, HIV prevalence was $1.0 \%$ when none of the risk factors were positive (Score 0 ) compared to $3.2 \%$ when at least one factor (Score $\geq 1$ ) was present and $8.0 \%$ when $\geq 4$ risk factors were present. Sensitivity, specificity, PPV, and NPV were $82.3 \%$ (78.6\%-85.9\%), 41.9\% (41.1\%-42.7\%), 3.2\% (2.8\%-3.6\%), and 99.0\% (98.8\%-99.3\%), respectively. The use of a tool containing conventional risk factors (all except those related with working and sleeping away) was found to have higher AUC compared to the use of all risk factors ( $p$ value $<0.001$ ), with corresponding sensitivity, specificity, PPV, and NPV of 63.5\% (58.9\%-68.1\%), 66.2\% (65.5\%-67.0\%), 4.2\% (3.6\%-4.8\%), and $98.7 \%(98.5 \%-98.9 \%)$, respectively.

\section{Conclusion}

Use of a screening tool containing conventional risk factors improved HIV testing yield compared to doing universal testing. Prioritizing people who fulfil multiple risk factors should be explored further to improve HIV testing yield. 


\section{Introduction}

HIV testing is the gate way for case finding, care and treatment as well as prevention services for high risk individuals. [1-3] Over the years remarkable progress has been made to diagnose infected people and put them on treatment. To date, Eastern and Southern African countries have coverage of $87 \%(77 \%-95 \%)$ for the first 90 while the coverage is $68 \%(54 \%-87 \%)$ for Central and Western African countries. [4] This correlates with high uptake of HIV testing across these countries. Prior HIV testing among surveyed men and women $15-49$ years was $62 \%$ and $74 \%$ for Eastern, Southern and Central African countries, respectively from 2015-2018. It was much lower for Western African countries at 31\% for women and 16\% for men. $[5,6]$

Maintaining such high testing coverage or conducting door-to-door testing in high risk communities is not feasible because of the limitation of funding available for HIV programs considering flattening of global support for HIV programs especially that of PEPFAR over the past 10 years. [7, 8] As a result of that, a strategic shift has been made to implement targeted HIV testing with the aim of getting high testing yield per dollar spent on HIV test kit in many country HIV programs including high burden countries with the aim of putting as many infected people on treatment and reducing new infection and mortality in the process. [9]

A number of HIV risk factors have been identified and in use to effect targeted HIV testing of at risk people. The World Health Organization (WHO) recommends HIV testing for clients having sexually transmitted infection (STI), viral hepatitis, tuberculosis (TB); key populations including commercial sex workers, men having sex with men, and IV drug users; clients with symptoms or medical conditions that could indicate HIV infection, including presumed and confirmed TB cases. [1, 2] Other risk factors known to increase risk of HIV infection include having multiple sexual partners [10,11], being divorced, separated or widowed (DSW) [12], history of being a client of a sex worker [13], having cervical Ca [14], being partners with known infected person [15].

A number of HIV risk assessment tools were validated in different settings in an effort to determine best options to identify HIV infected adults. $[10,16,17]$ These tools often don't include risk factors recommended by the $\mathrm{WHO}$ and in use in high prevalence countries. Knowing the performance and limitation of a risk screening tool containing all common HIV risk factors is crucial to determine case finding strategies that better fit routine implementation setting and assess quality of testing services both in clinical and community settings. This study aims to:

1. determine the performance of a hypothetical HIV risk assessment tool that contains conventional HIV risk factors to identify undiagnosed HIV + adults and adolescents $>14$ years,

2. determine the performance of a hypothetical HIV risk assessment tool that contains all potential HIV risk factors to identify undiagnosed HIV + adults and adolescents $>14$ years,

3. determine the performance of a hypothetical HIV risk assessment tool that contains only statistically significant HIV risk factors to identify undiagnosed HIV positive adults and adolescents $>14$ years 
4. determine which of the above three tools is better in terms of overall performance to identify undiagnosed HIV positive adults and adolescents $>14$ years

5. determine if the presence of multiple HIV risk factors in one person improves performance of risk assessment tool to identify undiagnosed HIV positive adults and adolescents $>14$ years.

\section{Materials And Methods}

Study setting and design: This is a cross sectional study based on secondary analysis of data from two community based household surveys that were conducted in Zambia (2016) and Tanzania (2016-2017). These surveys were Population-Based HIV Impact Assessment (PHIA) studies conducted with PEPFAR support. $[18,19]$

Study period: The surveys were conducted during 2016-2017.

Inclusion criteria: adolescents and adults $>14$ years who have matching interview and biomarker datasets (HIV testing result) and who had never tested for HIV prior the survey were included.

Sample size: was calculated to allow comparison between areas under receiver operating curves (ROC) between two different risk assessment tools. Sample size was calculated to be 1,363 assuming AUC1 = 0.65 , AUC2 $=0.6$, alpha $=0.05$, power $=80 \%$, correlation in positive group $=0.4$, and correlation in negative group $=0.4$. [21]

HIV risk factors: the following variables were considered in different HIV risk assessment tools to generate tool with better sensitivity, specificity, and positive predictive value (PPV+)

- being divorced, separated or widowed (DSW),

- having an HIV + spouse,

- having paid work within 12 months of the survey,

- slept away from home for at least a month within 12 months of the survey,

- had multiple sexual partners within 12 months of the survey,

- had ever sold sex,

- paid for sex within 12 months of the survey,

- had sexually transmitted infection (STI) within 12 months of the survey,

- diagnosed with cervical cancer,

- being a tuberculosis (TB) suspect within 12 months of the survey which meant having any of the following symptoms: cough, fever, night sweats or weight loss

- had TB disease, past or present, and

- being very sick for at least 3 months within 12 months of the survey, that is being too sick to work or do normal activities. 


\section{HIV risk assessment tools examined:}

Four different hypothetical tools were considered in the validation:

Tool 1: A tool that contained all conventional and any newly identified statistically significant risk factors that predicted HIV infection status in individuals never tested for HIV,

Tool 2: A tool that contained only statistically significant risk factors that were identified by purposeful selection of variables using logistic regression model,

Tool 3: A tool that contained conventional risk factors only, and

Tool 4: A tool that contained conventional risk factors and a combination of newly identified risk factors.

HIV testing: was offered for everyone in the survey and performed for all consenting adults and adolescents $>14$ years during the survey. Known HIV + status was further confirmed through the use of antiretroviral markers within the blood. Those with anti-retroviral markers were excluded from the study.

\section{Data analysis}

Data was obtained from the public domain of PHIA website [22] and analyzed using Stata 14.0 statistical software. First, risk factors that had association with HIV infection among those who never tested for HIV were identified using Chi Square test. To develop scores for a risk assessment tool, appropriate screening items were selected and coded one when the risk factor was present and zero when it was not and the total score calculated for each individual as the sum of the numerical values of the screening items included within a tool. For instance, for the first screening tool where all risk factors were included, the minimum score was 0 while the potential maximum was 12 . Chi Square test was also done to examine if having risk screening score of $\geq 1, \geq 2, \geq 3$, or $\geq 4$ was associated with HIV infection. Sampling weights were used to adjust statistical values taking into account complex sampling design used in PHIA surveys. [20]

To determine the optimal cut-off for the screening tool that will enable identification of people at risk of HIV infection, a receiver operating characteristic curve (ROC) was plotted. The area under the ROC (Receiver Operating Characteristic) curve (AUC) and corresponding sensitivity, specificity, positive predictive (PPV) and negative predictive values (NPV) by using the screening tool at different level of scores were determined. ROC comparison statistics was used to statistically test equality between AUC of the different scores. For the score selected to be having the best combination of sensitivity, specificity, PPV, NPV and AUC, similar analysis was conducted to see if age, gender, and residence affected AUC. This was done by doing stratified analysis of AUC using the stated variables.

Finally, to compare and select between the different risk assessment tools, test of quality of AUC was done. Number needed to test to identify one HIV infected person (NNT+) was also calculated to see if risk assessment tools reduced this number compared to universal testing. To select appropriate variables for the second tool, purposeful selection of variables was done using during regression model building. Those with $p$-value $<0.20$ during bi-variable analysis were included in the final model and examined. Level of significance was set at 0.05 . 
Ethics statement: all surveys had written informed consent, both for interview and blood collection for all participating adults. Parents consented for their children. All databases don't have individual identifiers like names or addresses that can be used to identify people.

\section{Results}

Of 68,564 adults and adolescents > 14 years included in the Tanzania and Zambia PHIA studies, 55,340 had a matching interview and biomarker (including HIV testing) datasets. Of these, 39,103 (70.7\%), had previously been tested for HIV and $181(0.3 \%)$ had missing previous HIV testing data, and hence excluded from the analysis. Of the remaining 16,056, 15160 (94.4\%) were tested for HIV. Excluding those who didn't have sampling weights, the final study sample was 14,820 . (Fig. 1)

Compared to individuals who were eligible for inclusion in this study but had missing HIV testing result, those who were tested for HIV during the survey were likely to be older, male, from urban area. They were also less likely to have multiple sexual partners or sexually transmitted infection in the past 12 months. (Supplementary Material Table 1)

Of 14,820 study participants, $57.8 \%$ were men, and had a median age of 30 (IQR: $21-24)$. HIV prevalence was $2.3 \%$ (95\% confidence interval (CI): 2.0-2.6). HIV prevalence was higher for the age category 25-49, among women, and in urban settings. All HIV risk factors, except for those with Presumptive TB, TB disease, or chronic illness, were found to be statistically significant predictors of HIV infection in individuals who were never tested for HIV. (Table 1)

Figure 2 summarizes HIV prevalence by risk factor. The highest was recorded for people who sold sex (13.5\%), followed by spouses of HIV infected adults (11\%) and those who were divorced, separated, or widowed $(6.1 \%)$. The presence of other risk factors had HIV testing yield ranging from $3.1 \%-5.5 \%$. TB in the past 10 years had a testing yield of $33.3 \%$ for Zambia compared to $3.7 \%$ for those without TB in the past 10 years, $p$ value $<0.001$ (data not shown). 
Table 1

Determinants of HIV Infection among adults and adolescents $>14$ years who were never tested for HIV before PHIA Surveys conducted in Zambia (2016) and Tanzania (2016-2017)

\begin{tabular}{|c|c|c|c|c|}
\hline Variable & Response & Total, $\mathbf{n}$ & HIV+, n (\%) & $P$ value \\
\hline \multirow[t]{3}{*}{ Age } & $15-24$ & 8,114 & $49(0.6 \%)$ & $<0.001$ \\
\hline & $25-49$ & 3,443 & $196(5.7 \%)$ & \\
\hline & $50+$ & 3,263 & $95(2.9 \%)$ & \\
\hline \multirow[t]{2}{*}{ Gender } & Male & 8,567 & $162(1.9 \%)$ & 0.002 \\
\hline & Female & 6,253 & $176(2.8 \%)$ & \\
\hline \multirow[t]{2}{*}{ Residence } & Urban & 4,707 & $130(2.8 \%)$ & 0.026 \\
\hline & Rural & 10,113 & $207(2.1 \%)$ & \\
\hline \multirow[t]{4}{*}{ Education } & No education & 2,647 & $82(3.1 \%)$ & 0.001 \\
\hline & Primary & 8,182 & $197(2.4 \%)$ & \\
\hline & Secondary & 3,859 & $55(1.4 \%)$ & \\
\hline & Tertiary & 132 & $4(3.1 \%)$ & \\
\hline \multirow[t]{5}{*}{ Wealth Quintile } & Lowest & 3,398 & $73(2.1 \%)$ & 0.038 \\
\hline & Secondary & 3,412 & $70(2.0 \%)$ & \\
\hline & Middle & 3,081 & $73(2.4 \%)$ & \\
\hline & Fourth & 2,432 & 79 (3.2\%) & \\
\hline & Highest & 2,496 & $43(1.7 \%)$ & \\
\hline \multirow[t]{2}{*}{ Marital status } & Single, Married & 13,045 & $230(1.8 \%)$ & $<0.001$ \\
\hline & $\mathrm{DSW}^{\$}$ & 1,775 & $108(6.1 \%)$ & \\
\hline \multirow[t]{2}{*}{ Spouse is Known to have HIV } & No & 14,777 & $333(2.3 \%)$ & 0.001 \\
\hline & Yes & 43 & $5(11.0 \%)$ & \\
\hline \multirow[t]{2}{*}{ Having Paid Work* } & No & 9,692 & $172(1.8 \%)$ & $<0.001$ \\
\hline & Yes & 5,128 & $166(3.2 \%)$ & \\
\hline \multirow[t]{2}{*}{ Slept Away from Home for $>1$ month* } & No & 12,939 & $273(2.1 \%)$ & 0.015 \\
\hline & Yes & 1,881 & $65(3.5 \%)$ & \\
\hline
\end{tabular}

\$Divorced, Separated, or Widowed; *within the last 12 months of the survey,

\#Cough, fever, night sweats, or weight loss 


\begin{tabular}{|c|c|c|c|c|}
\hline Variable & Response & Total, $\mathbf{n}$ & HIV+, n (\%) & $P$ value \\
\hline \multirow[t]{2}{*}{ Multiple Sexual Partners* } & No & 12,970 & $282(2.2 \%)$ & 0.042 \\
\hline & Yes & 1,850 & $58(3.1 \%)$ & \\
\hline \multirow[t]{2}{*}{ Ever Sold Sex } & No & 14,786 & $333(2.3 \%)$ & $<0.001$ \\
\hline & Yes & 34 & $5(13.5 \%)$ & \\
\hline \multirow[t]{2}{*}{ Paid for Sex* } & No & 14,100 & $304(2.2 \%)$ & $<0.001$ \\
\hline & Yes & 720 & $36(4.9 \%)$ & \\
\hline \multirow[t]{2}{*}{ Sexually transmitted infection* } & No & 13,385 & $274(2.0 \%)$ & $<0.001$ \\
\hline & Yes & 1,435 & $65(4.5 \%)$ & \\
\hline \multirow[t]{2}{*}{ Has Cervical Cancer } & No & 14,755 & 335 (2.3\%) & 0.025 \\
\hline & Yes & 65 & $4(5.5 \%)$ & \\
\hline \multirow[t]{2}{*}{ Presumptive TB ${ }^{\# *}$} & No & 14,460 & $326(2.3 \%)$ & 0.215 \\
\hline & Yes & 360 & $12(3.3 \%)$ & \\
\hline \multirow[t]{2}{*}{ TB disease, current or past } & No & 14,639 & $330(2.3 \%)$ & 0.055 \\
\hline & Yes & 181 & $8(4.4 \%)$ & \\
\hline \multirow[t]{2}{*}{ Sick for the past 3 months* } & No & 14,242 & $317(2.2 \%)$ & 0.078 \\
\hline & Yes & 578 & $22(3.8 \%)$ & \\
\hline \multicolumn{2}{|l|}{ Total } & 14,820 & $338(2.3 \%)$ & \\
\hline \multicolumn{5}{|c|}{ \$Divorced, Separated, or Widowed; *within the last 12 months of the survey, } \\
\hline \multicolumn{5}{|c|}{ \#Cough, fever, night sweats, or weight loss } \\
\hline
\end{tabular}

Looking at the performance of Tool 1 at different risk score levels, those individuals having one or more risk factors were found to have an HIV prevalence of $3.2 \%$ which increased with increasing cut-off: $4.4 \%, 5.6 \%$, 7.9\% HIV prevalence for two, three, and four cut-off scores respectively. (Table 2) Fig. 3 indicates the ROC curve comparing the different cut-off points for Tool 1. Area under the curve (AUC) can be seen to reduce as the risk assessment cut-off increases. A score of $\geq 1$ was found to have the highest sensitivity at $82.3 \%$ (95\% Cl: $78.6 \%-85.9 \%)$ with the next score of $\geq 2$ having nearly half the sensitivity at $46.8 \%(42.0 \%-51.6 \%)$. The specificity was higher for a higher cut-off. Positive predictive value was higher for a higher cut-off point while negative predictive value was comparable between all cut-0ff scores. 
Table 2

Association of HIV Risk Scores with HIV Infection using a tool that contains all HIV Risk Factors for Adults and Adolescents >

14 years who were never tested for HIV before PHIA Surveys conducted in Zambia (2016) and Tanzania (2016-2017)

\begin{tabular}{|lllll|}
\hline Risk Score & Response & Total, $\mathbf{n}$ & HIV+, $\mathbf{n}(\%)$ & P value \\
\hline Score $\geq \mathbf{1}$ & No & 6,122 & $59(1.0 \%)$ & $<0.001$ \\
\hline Yes & 8,698 & $279(3.2 \%)$ & \\
\hline Score $\geq 2$ & No & 11,238 & $179(1.6 \%)$ & $<0.001$ \\
\hline Yes & 3,582 & $159(4.4 \%)$ & \\
\hline Score $\geq 3$ & No & 13,556 & $267(2.0 \%)$ & $<0.001$ \\
\hline & Yes & 1,264 & $71(5.6 \%)$ & \\
\hline & No & 14,445 & $308(2.1 \%)$ & $<0.001$ \\
\hline
\end{tabular}

Compared to a cut-off score of $\geq 1$, AUC was comparable with a cut-off score of $\geq 2$ while it was lower for those with higher cut-off scores ( $p$ value $<0.001$ ). (Table 3) The AUC was comparable by age, gender, and residence. (Table 4)

Table 3

Sensitivity, Specificity, Positive Predictive Value (PPV+), and Negative Predictive Value (NPV-) for HIV Risk Screening Tool Containing Various Combinations of All Risk Factors

\begin{tabular}{|c|c|c|c|c|c|c|}
\hline $\begin{array}{l}\text { Screening } \\
\text { Tool } \\
\text { Score* }\end{array}$ & Sensitivity & Specificity & PPV & NPV & AUC** & $\begin{array}{l}\mathrm{P} \\
\text { value***}\end{array}$ \\
\hline Score $\geq 1$ & $\begin{array}{l}82.3 \% \\
(78.6 \%-85.9 \%)\end{array}$ & $\begin{array}{l}41.9 \% \\
(41.1 \%-42.7 \%)\end{array}$ & $\begin{array}{l}3.2 \% \\
(2.8 \%-3.6 \%)\end{array}$ & $\begin{array}{l}99.0 \% \\
(98.8 \%-99.3 \%)\end{array}$ & 0.6116 & \\
\hline Score $\geq 2$ & $\begin{array}{l}46.8 \% \\
(42.0 \%-51.6 \%)\end{array}$ & $\begin{array}{l}76.4 \% \\
(75.7 \%-77.1 \%)\end{array}$ & $\begin{array}{l}4.4 \% \\
(3.7 \%-5.1 \%)\end{array}$ & $\begin{array}{l}98.4 \% \\
(98.2 \%-98.6 \%)\end{array}$ & 0.6159 & 0.7137 \\
\hline Score $\geq 3$ & $\begin{array}{l}21.0 \% \\
(17.1 \%-24.9 \%)\end{array}$ & $\begin{array}{l}91.8 \% \\
(91.3 \%-92.2 \%)\end{array}$ & $\begin{array}{l}5.6 \% \\
(4.3 \%-7.0 \%)\end{array}$ & $\begin{array}{l}98.0 \% \\
(97.8 \%-98.3 \%)\end{array}$ & 0.5599 & $<0.001$ \\
\hline Score $\geq 4$ & $\begin{array}{l}8.9 \% \\
(6.2 \%-11.6 \%)\end{array}$ & $\begin{array}{l}97.6 \% \\
(97.4 \%-97.9 \%)\end{array}$ & $\begin{array}{l}8.0 \% \\
(5.1 \%-10.9 \%)\end{array}$ & $\begin{array}{l}97.9 \% \\
(97.6 \%-98.1 \%)\end{array}$ & 0.5332 & $<0.001$ \\
\hline \multicolumn{7}{|c|}{$\begin{array}{l}\text { * Score } \geq 1 \text { means an individual who has one or more risk factors for HIV; }{ }^{* *} \text { AUC = Area under the Curve } \\
\text { of a Receiver Operating Curve; }\end{array}$} \\
\hline
\end{tabular}


Table 4

Comparison of Receiver Operating Characteristics Curve for HIV Risk Screening Tool (Score $\geq 1$ ) by Age, Gender, and Residence for Adults and Adolescents > 14 years who were never tested for HIV before PHIA Surveys conducted in Zambia (2016) and Tanzania (2016-2017)

\begin{tabular}{|lllll|}
\hline Variable & Response & Observation & Area Under ROC Curve & P value \\
\hline Age & $15-24$ & 7,868 & 0.5756 & 0.6033 \\
\hline & $25-49$ & 3,507 & 0.5705 & \\
\hline Gender & Male & 7,945 & 0.6119 & 0.6448 \\
\hline \multirow{2}{*}{ Residence } & Urban & 4,461 & 0.6070 & \\
& Rural & 10,359 & 0.6137 & 0.7531 \\
\hline
\end{tabular}

Figure 4 summarizes relationship between eligibility, sensitivity, and PPV or HIV testing yield. Eligibility for HIV test decreased with increasing of risk score cut-offs: $56 \%$ would be eligible with a cut-off score of $\geq 1$ while it was $2 \%$ for a cut-off score of $\geq 4$. HIV testing positivity (PPV) and sensitivity or eligibility was negatively correlated with both going down with increasing cut-off score while PPV increased.

In the tool that contained only statistically significant risk factors (Tool 2), being DSW (odds ratio (OR): 3.9 (95\% Cl: 2.9-5.2); p-value < 0.001), being spouse of a known HIV + person (OR: 6.1 (95\% Cl:2.0-19.1); pvalue $=0.003)$, having history of selling sex for money (OR: 7.7 (95\% Cl:3.6-16.3); p-value < 0.001), having sexually transmitted infections in the past 12 months (OR: 2.1 (95\% Cl:1.4-3); p-value < 0.001), and working in the past 12 months (OR: 2.1 (95\% Cl:1.4-3); p-value< 0.001) were included in the final model. Tool 4 that contained customized risk factors, the combination of risk factors having paid work in the past year and sleeping away from home for more than a month in the past 12 months were combined as predictors in addition to conventional risk factors. Having a paid work and sleeping away from home were statistically significant predictors of undiagnosed HIV infection (OR: 1.8 (95\% Cl: 1.1-3.0)).

Looking at the different risk assessment tools, all were statistically significant predictors of HIV infection with $\mathrm{p}$-value $<0.001$. For all tools, if none of the risk factors were present, HIV prevalence was low at 1.0$1.3 \%$. (Table 5) Sensitivity was better for Tool 1 but the corresponding specificity was the lowest. AUC was better for all other tools as compared to this tool and the difference was much higher for Tools 3 and 4 ( $p$ value $<0.001$ ). (Table 6) PPV or HIV testing yield was highest for Tools 3 and 4 at $4.2 \%$ and $4.0 \%$, respectively, if at least one risk factor was present. Tool 3 has the lowest proportion of people eligible for testing at $34 \%$ the highest being for tool 1 at 59\%. (Table 5) Number needed to test (NNT+) was 24 for Tool 3 while it was 43 if universal testing was used. 
Table 5

Association of Risk Scores with HIV Infection using a tool that contains all HIV Risk Factors for Adults and Adolescents > 14 years who were never tested for HIV before PHIA Surveys conducted in Zambia (2016) and Tanzania (2016-2017)

\begin{tabular}{|c|c|c|c|c|}
\hline Risk Assessment Tool & Response & $\begin{array}{l}\text { Total, } \\
\mathbf{n}\end{array}$ & $\begin{array}{l}\text { HIV+, n } \\
(\%)\end{array}$ & $\begin{array}{l}P \\
\text { value }\end{array}$ \\
\hline \multirow[t]{2}{*}{ Tool 1: All Risk Factors: Score $\geq 1$} & No & 6,122 & $\begin{array}{l}59 \\
(1.0 \%)\end{array}$ & $\dot{0} 001$ \\
\hline & Yes & 8,698 & $\begin{array}{l}279 \\
(3.2 \%)\end{array}$ & \\
\hline \multirow[t]{2}{*}{$\begin{array}{l}\text { Tool 2: Statistically Significant Risk Factors in final model: } \\
\text { Score } \geq 1\end{array}$} & No & 7,850 & $\begin{array}{l}90 \\
(1.2 \%)\end{array}$ & $\hat{0} .001$ \\
\hline & Yes & 6,970 & $\begin{array}{l}247 \\
(3.6 \%)\end{array}$ & \\
\hline \multirow[t]{2}{*}{ Tool 3: Conventional Risk Factors: Score $\geq 1$} & No & 9,717 & $\begin{array}{l}123 \\
(1.3 \%)\end{array}$ & $\dot{0} 001$ \\
\hline & Yes & 5,103 & $\begin{array}{l}215 \\
(4.2 \%)\end{array}$ & \\
\hline \multirow[t]{2}{*}{ Tool 4: Customized Tool: Score $\geq 1$} & No & 9,294 & $\begin{array}{l}117 \\
(1.3 \%)\end{array}$ & ¿. 001 \\
\hline & Yes & 5,526 & $\begin{array}{l}221 \\
(4.0 \%)\end{array}$ & \\
\hline
\end{tabular}


Table 6

Sensitivity, Specificity, Positive Predictive Value (PPV+), and Negative Predictive Value (NPV-) for each potential HIV Risk Screening Tool for Adults and Adolescents > 14 years who were never tested for HIV before PHIA Surveys conducted in Zambia (2016) and Tanzania (2016-2017)

\begin{tabular}{|c|c|c|c|c|c|c|}
\hline $\begin{array}{l}\text { Risk Factor } \\
\text { Selection } \\
\text { Strategy }\end{array}$ & Sensitivity & Specificity & PPV & NPV & AUC** & 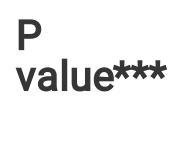 \\
\hline $\begin{array}{l}\text { Tool 1: All } \\
\text { risk factors }\end{array}$ & $\begin{array}{l}82.3 \% \\
(78.6 \%-85.9 \%)\end{array}$ & $\begin{array}{l}41.9 \% \\
(41.1 \%-42.7 \%)\end{array}$ & $\begin{array}{l}3.2 \% \\
(2.8 \%-3.6 \%)\end{array}$ & $\begin{array}{l}99.0 \% \\
(98.8 \%-99.3 \%)\end{array}$ & 0.6116 & \\
\hline $\begin{array}{l}\text { Tool 2: } \\
\text { Statistically } \\
\text { significant } \\
\text { only\# }\end{array}$ & $\begin{array}{l}73.4 \% \\
(69.1 \%-77.6 \%)\end{array}$ & $\begin{array}{l}53.6 \% \\
(52.8 \%-54.4 \%)\end{array}$ & $\begin{array}{l}3.6 \% \\
(3.1 \%-4.0 \%)\end{array}$ & $\begin{array}{l}98.9 \% \\
(98.6 \%-99.1 \%)\end{array}$ & 0.6267 & 0.035 \\
\hline $\begin{array}{l}\text { Tool 3: } \\
\text { Conventional } \\
\text { risk factors }\end{array}$ & $\begin{array}{l}63.5 \% \\
(58.9 \%-68.1 \%)\end{array}$ & $\begin{array}{l}66.2 \% \\
(65.5 \%-67.0 \%)\end{array}$ & $\begin{array}{l}4.2 \% \\
(3.6 \%-4.8 \%)\end{array}$ & $\begin{array}{l}98.7 \% \\
(98.5 \%-98.9 \%)\end{array}$ & 0.6469 & $<0.001$ \\
\hline $\begin{array}{l}\text { Tool 4: } \\
\text { Customized } \\
\text { tool* }\end{array}$ & $\begin{array}{l}65.5 \% \\
(61.0 \%-70.1 \%)\end{array}$ & $\begin{array}{l}63.4 \% \\
(62.6 \%-64.2 \%)\end{array}$ & $\begin{array}{l}4.0 \% \\
(3.5 \%-4.5 \%)\end{array}$ & $\begin{array}{l}98.7 \% \\
(98.5 \%-99.0 \%)\end{array}$ & 0.6412 & $<0.001$ \\
\hline
\end{tabular}

\#Only those included in the final model were considered; ${ }^{*}$ Customized tool = Conventional risk factors + Working for a payment in the past 12 months and Sleeping away from home for at least 1 month in the past 12 months of the survey. ${ }^{\star \star} \mathrm{AUC}=$ Area under the Curve of a Receiver Operating Curve;

*** $\mathrm{P}$ value compares AUC for a given risk assessment tool with the reference tool that contains all risk factors.

\section{Discussion}

We set out to validate HIV risk assessment tool used for adults. In that process we tried various combinations of risk factors in different tools for best possible outcome. The final tool we recommend for use contains conventional risk factors. That screening tool showed a moderate sensitivity and specificity for identifying infected adults at household level. Using this screening tool, the number needed to test to diagnose one HIV infected adult was 24 down from 43 if universal testing was used.

Looking at individual risk factors, the prevalence of HIV in those who never tested for HIV remained to be high compared to those without risk factors except for TB related risk factors and chronic illness. Two risk factors that stood out with having testing yield of $>10 \%$ were selling sex for money and having an HIV + spouse. This is comparable to reported prevalence of $12-20 \%$ among FSWs in the study countries. [23] ICT for spouses records even higher testing yield at 32\% in program settings. [24] Marital status is an important risk factor. Being divorced widowed or separated was found to be the third highest risk factor with a yield of $6.1 \%$. DSWs are easily identifiable at community level and can be used to identify at risk people at community or facility level. It is already a risk factor in many countries. $[25,26]$ Cervical cancer is an important risk factor since Human Papiloma Virus, which is a sexually transmitted viral infection, is the causative agent. [27] Co-infection with HIV was $5.5 \%$ in this study. Having multiple sexual partners was 
found to have a relatively lower prevalence at $3.1 \%$. This may be due to the higher condom use during casual sex with a non-regular partner. $[28,29]$

Lifetime TB disease was not statistically significant at the 0.05 cut-off. This should not be misinterpreted as TB not being a risk factor. Data on year of TB diagnosis was present only for Zambia and when we did analysis comparing TB diagnosed in the past 10 years to those who never had TB, or who had TB before 10 years, TB prevalence was much higher at 33.3\% prevalence. That should be used in practice instead of lifetime TB disease.

Presumptive TB was not predictor of HIV infection. That is probably because it was defined broadly especially for cough. A definition of cough $>2$ weeks may make improve the positivity. In studies where the later definition was used, the positivity was found to be higher. [30,31]

Adults having multiple risk factors were found to have high testing yield and were a small fraction of the total assessed. This should be further explored further to identify additional risk factors. A very good example in current use by different case finding and prevention programs is being long distance truck driver, who are likely to sleep away from home, and have multiple sexual partners including sex workers. [32, 33]

This study also provides some form of reference for the percentage of people who are potentially eligible for HIV testing fulfilling at least one of the conventional risk factors among those who never tested for HIV. In this study, $34.4 \%$ adults who never tested for HIV would be eligible for testing. That is around $9.1 \%$ of the initial number of adults interviewed. This provides a reference value with which to compare community HIV case finding interventions when such risk factors are used. However, it would not be advisable to test this much adults as it wouldn't be cost effective. A more targeted approach focusing on sex workers and their clients, partners of known HIV + index cases, DSWs, and TB cases would be important starting points. [2]

Eliciting some of the risk factors especially those related to sexual history may need some experience especially when implementing the risk assessment tool at community level. The use of health extension workers or community health workers who formally do health interventions may help. At facility level where these risk factors are often used maintaining quality of counselling needs to be ensured through ongoing training and on job coaching. Some of the risk factors are treated in speciality clinics like TB in TB clinic, or STI and cervical cancer in gynaecology clinics for women. This will make it easier to implement universal testing for these groups by providing integrated testing services.

The large number of study participants was one of the strengths of the study. Missing data was minimal and was not related to the risk factors being studied. The performance of the final tool was found to be independent of age, gender, and residence making the use of the tool applicable in different scenarios. Some of the risk factors were captured a little different from what is used in actual settings. All parameters of screening tool are likely to improve if the presence of the following risk factors was determined for the past 10 years just like what we did with TB instead of just the past 12 months: multiple sexual partners, STI, and paid for sex.

\section{Conclusion}


Use of a screening tool containing conventional risk factors improved HIV testing yield compared to doing universal testing. The use of multiple risk factors to improve HIV testing yield should be explored further.

\section{Abbreviations}

AUC: Area under the Curve; Cl: Confidence Interval; DSW: Divorced, Separated, Widowed; HIV: Human Immunodeficiency Virus; ICT: Index case testing; IQR: Interquartile range; NNT: Number needed to test; NPV: Negative Predictive Value; OR: Odds ratio; PEPFAR: Presidents Emergency Plan for AIDS Relief; PHIA: Population-based HIV Impact Assessment; PPV: Positive Predictive Value; ROC: Receiver Operating Characteristics; STI: Sexually transmitted Disease; TB: Tuberculosis; WHO: World Health Organization;

\section{Declarations}

\section{Ethics approval and consent to participate}

Both PHIA surveys had written informed consent, both for interview and blood collection for all participating adults. Parents consented for adolescents. All datasets don't have individual identifiers like names or addresses that can be used to identify people. In addition, the study got a non-human subject determination from the Office of International Research Ethics of Family Health International (FHI360).

\section{Consent for publication}

Not applicable.

\section{Availability of data and materials}

All data generated or analyzed during this study are included in this published article as Additional File 1 in Excel format.

\section{Competing interests}

The authors declare that they have no competing interests.

\section{Funding}

The authors received no funding to conduct this study.

\section{Authors' contributions}

KDY originated the research idea, collected and analyzed the data; KDY \& JM contributed to data analysis and writing the manuscript; All authors read and approved the final manuscript.

\section{Acknowledgements}

Not applicable. 


\section{Author details}

${ }^{1}$ Department of HIV, Integrated Services for Health and Development Organization, Addis Ababa, Ethiopia;

${ }^{2}$ Global Health, Population and Nutrition, Family Health International, Washington DC, USA

\section{References}

1. World Health Organisation: WHO Guidelines on HIV Testing. 2015.

2. World Health Organisation: Consolidated Guidelines on HIV Prevention, Diagnosis, Treatment And Care For Key Populations. 2016.

3. World Health Organisation: Consolidated HIV Prevention, Care and Treatment Guideline. 2016.

4. UNAIDS: AIDS Info: Progress towards 90-90-90 targets (https://aidsinfo.unaids.org/). 2020.

5. ICF: The DHS Program STATcompiler. http://www.statcompiler.com. August 6 2020. 2020.

6. Maheu-Giroux M, Marsh K, Doyle CM, Godin A, Delaunay CL, Johnson LF, Jahn A, Abo K, Mbofana F, Boily M-C: National HIV testing and diagnosis coverage in sub-Saharan Africa: a new modeling tool for estimating the 'first 90'from program and survey data. AIDS (London, England) 2019, 33(Suppl 3):S255.

7. KFF: U.S. Federal Funding for HIV/AIDS: Trends Over Time (from: https://www.kff.org/hivaids/factsheet/u-s-federal-funding-for-hivaids-trends-over-time/). Accessed on August 7, 2020. 2020.

8. Shanaube K, Schaap A, Floyd S, Phiri M, Griffith S, Chaila J, Bock P, Hayes R, Fidler S, Ayles H: What works-reaching universal HIV testing: lessons from HPTN 071 (PopART) trial in Zambia. AIDS (London, England) 2017, 31(11):1555.

9. PEPFAR: Annual Report to Congress. 2019.

10. Balkus JE, Brown E, Palanee T, Nair G, Gafoor Z, Zhang J, Richardson BA, Chirenje ZM, Marrazzo JM, Baeten JM: An empiric HIV risk scoring tool to predict HIV-1 acquisition in African women. Journal of acquired immune deficiency syndromes (1999) 2016, 72(3):333.

11. Birri Makota RB, Musenge E: Factors associated with HIV infection in Zimbabwe over a decade from 2005 to 2015: an interval-censoring survival analysis approach. Frontiers in public health 2019, 7:262.

12. Ba DM, Ssentongo AE, Traore M, Ssentongo P: Prevalence of Human Immunodeficiency Virus and Its Sociodemographic, Knowledge and Behavioral Predictors among Women: A Cross-Sectional Population-Based Survey in Ivory Coast. of 2018, 6:2011-2012.

13. Fauk NK, Kustanti CY, Wulandari R, Damayani AD, Mwanri L: Societal determinants of HIV vulnerability among clients of female commercial sex workers in Indonesia. PloS one 2018, 13(11):e0207647.

14. Wu ES, Urban RR, Krantz EM, Mugisha NM, Nakisige C, Schwartz SM, Gray HJ, Casper C: The association between HIV infection and cervical cancer presentation and survival in Uganda. Gynecologic oncology reports 2020, 31:100516.

15. Dalal S, Johnson C, Fonner V, Kennedy CE, Siegfried N, Figueroa C, Baggaley R: Reaching people with undiagnosed HIV infection through assisted partner notification. AIDS (London, England) 2017, 31(17):2436. 
16. Smith DK, Pan Y, Rose CE, Pals SL, Mehta SH, Kirk GD, Herbst JH: A brief screening tool to assess the risk of contracting HIV infection among active injection drug users. Journal of addiction medicine 2015, 9(3):226.

17. Haukoos JS, Hopkins E, Bucossi MM, Lyons MS, Rothman RE, White DA, Al-Tayyib AA, Bradley-Springer L, Campbell JD, Sabel AL: Validation of a quantitative HIV risk prediction tool using a national HIV testing cohort. Journal of acquired immune deficiency syndromes (1999) 2015, 68(5):599.

18. Ministry of Health Z: Zambia Population-based HIV Impact Assessment (ZAMPHIA) 2016: Final Report. Lusaka. 2019.

19. (ZAC). TCfATZAC: Tanzania HIV Impact Survey (THIS) 2016-2017: Final Report. Dar es Salaam, Tanzania. 2018.

20. Population-based HIV Impact Assessment (PHIA) Data Use Manual. New York NJ.

21. MedCalc Statistical Software version 19.4.1 (MedCalc Software Ltd -O, -Belgium; https://www.medcalc.org; 2020).

22. The PHIA Project: Population-Based HIV Impact Assessment Datasets (accessed from: https://phiadata.icap.columbia.edu/files). 2020.

23. Chanda MM, Ortblad KF, Mwale M, Chongo S, Kanchele C, Kamungoma N, Fullem A, Dunn C, Barresi LG, Harling G: HIV self-testing among female sex workers in Zambia: a cluster randomized controlled trial. PLoS medicine 2017, 14(11):e1002442.

24. Reaching the unreachable: early results from index testing in Zambia in the CIRKUITS project. In: JOURNAL OF THE INTERNATIONAL AIDS SOCIETY: 2019: JOHN WILEY \& SONS LTD THE ATRIUM, SOUTHERN GATE, CHICHESTER P019 8SQ, W ... -14.

25. Ministry of Health: National Comprehensive HIV Prevention, Care and Treatment Training for Health care Providers. 2017.

26. Ministry of Health: The Kenya HIV Testing Services Guidelines (from http://www.hivst.org/files1/kenyahtsguidelines20151-160119080906.pdf). 2015.

27. Mayo Foundation for Medical Education and Research: Cervical cancer. symptoms and cause (from: https://www.mayoclinic.org/diseases-conditions/cervical-cancer/symptoms-causes/syc-20352501). 2020.

28. Zambia Statistics Agency - ZSA, Ministry of Health - MOH, University Teaching Hospital Virology Laboratory - UTH-VL, ICF: Zambia Demographic and Health Survey 2018. In. Lusaka, Zambia: ZSA, MOH, UTH-VL and ICF; 2020.

29. Ministry of Health CD, Gender, Elderly, Children - MoHCDGEC/Tanzania Mainland, Ministry of Health $\mathrm{MoH} /$ Zanzibar, National Bureau of Statistics - NBS/Tanzania, Office of Chief Government Statistician OCGS/Zanzibar, ICF: Tanzania Demographic and Health Survey and Malaria Indicator Survey 20152016. In. Dar es Salaam, Tanzania: MoHCDGEC, MoH, NBS, OCGS, and ICF; 2016.

30. Yotebieng M, Wenzi LK, Basaki E, Batumbula ML, Tabala M, Mungoyo E, Mangala R, Behets F: ProviderInitiated HIV testing and counseling among patients with presumptive tuberculosis in Democratic Republic of Congo. The Pan African Medical Journal 2016, 25. 
31. Kyaw KWY, Kyaw NTT, Kyi MS, Aye S, Harries AD, Kumar AM, Oo NL, Satyanarayana S, Aung ST: HIV testing uptake and HIV positivity among presumptive tuberculosis patients in Mandalay, Myanmar, 2014-2017. PloS one 2020, 15(6):e0234429.

32. Delany-Moretlwe S, Bello B, Kinross P, Oliff M, Chersich M, Kleinschmidt I, Rees H: HIV prevalence and risk in long-distance truck drivers in South Africa: a national cross-sectional survey. International journal of STD \& AIDS 2014, 25(6):428-438.

33. Botão C, Horth RZ, Frank H, Cummings B, Inguane C, Sathane I, McFarland W, Raymond HF, Young PW: Prevalence of HIV and associated risk factors among long distance truck drivers in Inchope, Mozambique, 2012. AIDS and Behavior 2016, 20(4):811-820.

\section{Figures}

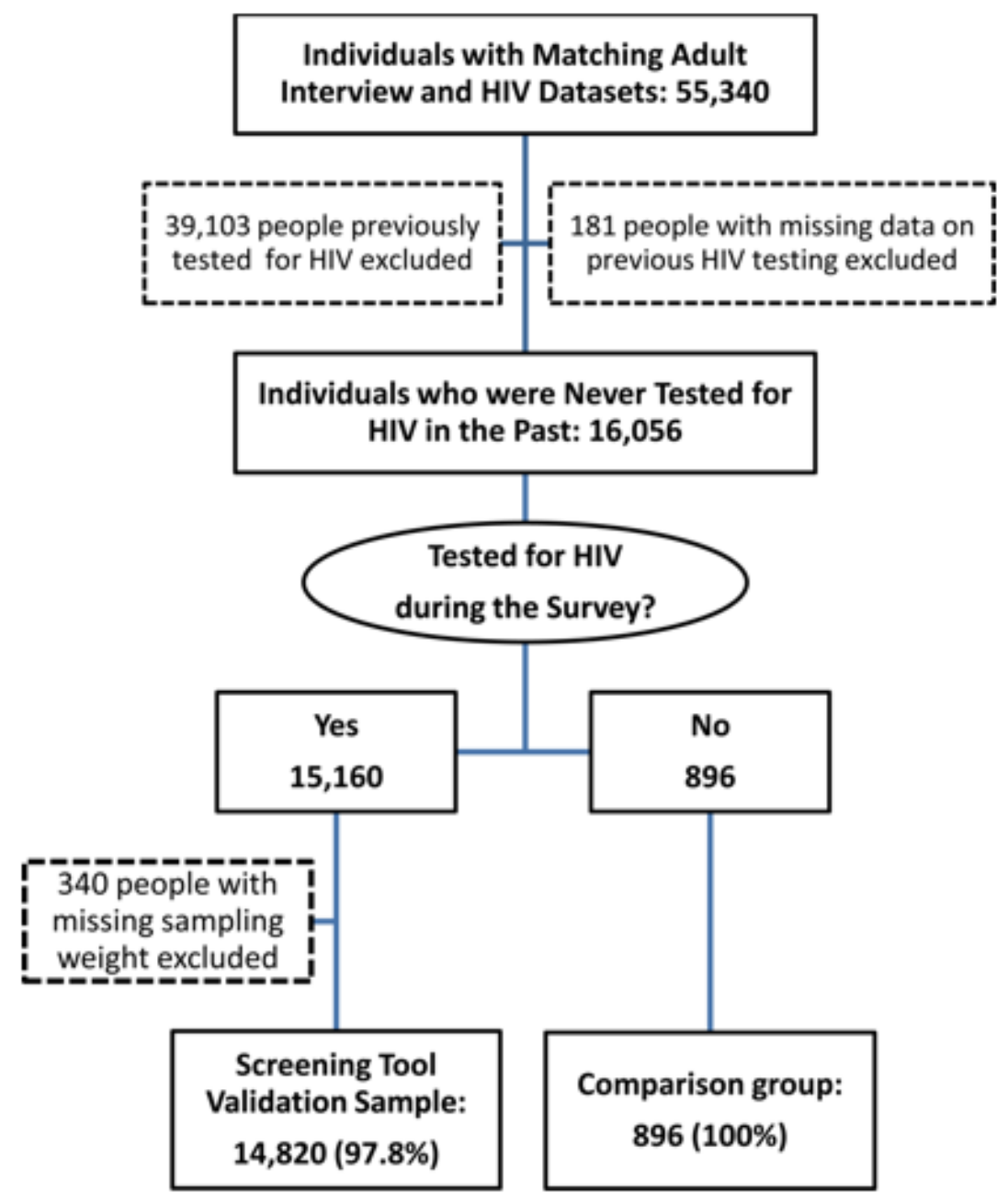

Figure 1

Selection of Study Sample 


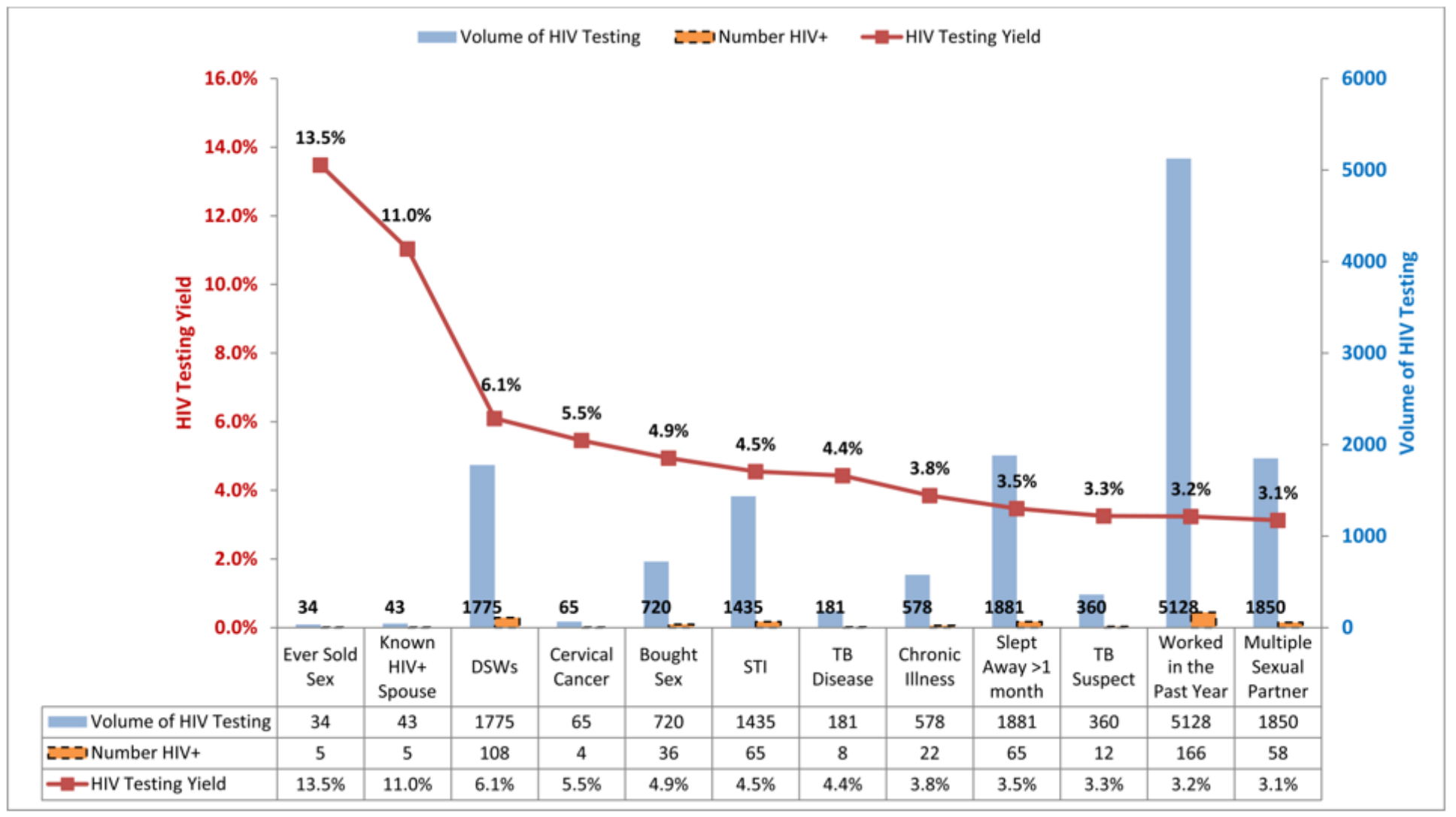

Figure 2

HIV Testing Yield by Risk Factors among Adults and Adolescents $>14$ years who were never tested for HIV before PHIA surveys conducted in Zambia (2016) and Tanzania (2016-2017) 


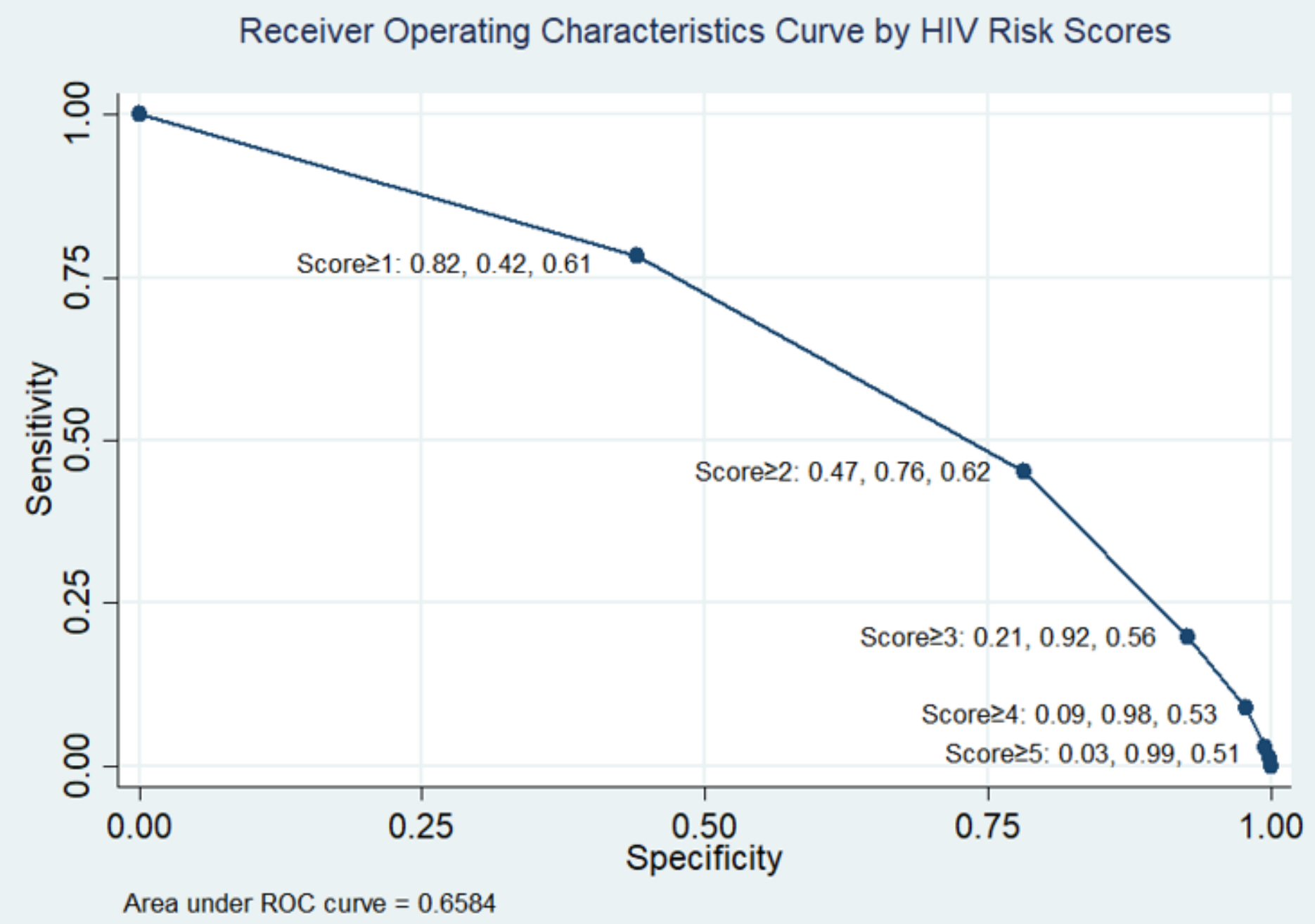

Figure 3

Receiver Operating Characteristics Curve by HIV Risk Scores for Adults and Adolescents $>14$ years who were never tested for HIV before PHIA Surveys conducted in Zambia (2016) and Tanzania (2016-2017). For each cut-off, sensitivity, specificity, and area under the curve are indicated. 


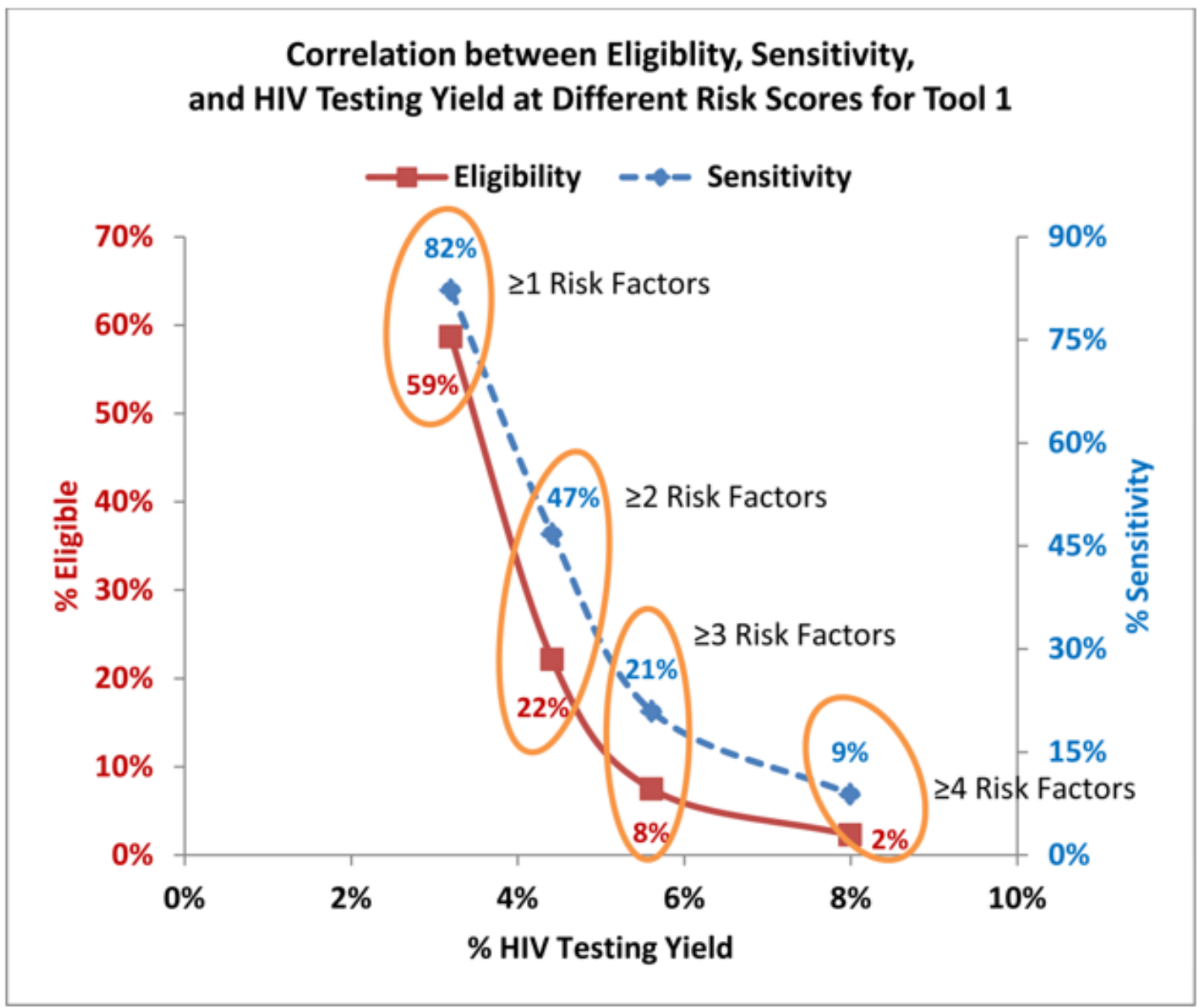

Figure 4

Relationship between Eligibility, Sensitivity, and HIV Testing Yield for a Risk Assessment Tool that contains all Risk Factors for Adults and Adolescents $>14$ years who were never tested for HIV before PHIA Surveys conducted in Zambia (2016) and Tanzania (2016-2017)

\section{Supplementary Files}

This is a list of supplementary files associated with this preprint. Click to download.

- SupplementaryMaterialTable1.docx 